\title{
Harassment di Lingkungan Kerja dalam Drama Eiji Harasumento Karya Uchidate Makiko
}

\author{
Kadek Sri Wahyuni ${ }^{*}$, Ni Luh Kade Yuliani Giri ${ }^{2}$, Silvia Damayanti ${ }^{3}$ \\ ${ }^{[123]}$ Prodi Sastra Jepang Fakultas Ilmu Budaya Unud \\ 1email: kadekwahyunni@gmail.com] [2[giri222000@yahoo.com] \\ 3 [silvia_damayanti@gmail.com] \\ *Corresponding Author
}

\begin{abstract}
Abstrak
Penelitian ini berjudul "Harassment di Lingkungan Kerja dalam Drama Eiji Harasumento Karya Uchidate Makiko". Tujuan penelitian ini adalah untuk mengetahui bentuk-bentuk harassment di tempat kerja yang tercermin dalam drama Eiji Harasumento. Selain itu, juga untuk mengetahui upaya tokoh dalam menghadapi harassment tersebut. Data yang terkumpul kemudian dianalisis dengan menggunakan metode deskriptif analisis. Terdapat tiga teori yang digunakan yaitu Teori Sosiologi Sastra dari Wiyatmi (2013), Teori Harassment dari Beran \& Li (2002) dan Teori Semiotika dari Danesi (2004). Hasil analisis data menunjukkan bahwa dalam drama Eiji Harasumento terjadi bentuk pelecehan yang berulang namun dilakukan oleh tokoh yang berbeda-beda. 70\% pelecehan merupakan pelecehan langsung sedangkan 30\% merupakan pelecehan tidak langsung. Pelecehan langsung secara verbal ditemukan sebanyak $85 \%$ dari keseluruhan pelecehan langsung. Sedangkan sebagian kecil ialah pelecehan langsung secara nonverbal. Sebagian besar pelecehan langsung dilakukan oleh atasan maupun kolega terhadap tokoh wanita, namun terdapat pula data yang menunjukkan pelecehan yang dilakukan bawahan terhadap atasan dalam drama Eiji Harasumento. Sedangkan keseluruhan pelecehan tidak langsung dilakukan oleh sesama wanita baik oleh atasan maupun wanita yang berkedudukan sama. Kemudian upaya tokoh dalam mengatasi pelecehan sebagian besar ditunjukkan oleh tokoh wanita baik secara langsung maupun tidak langsung.
\end{abstract}

Kata kunci : pelecehan langsung, pelecehan tidak langsung, pelecehan di tempat kerja

\begin{abstract}
The tittle of this research is "Workplace Harassment in Eiji Harasumento drama by Makiko Uchidate". The purpose of this research is to know the forms of harassment in the workplace which is reflected in Eiji Harasumento drama and also to know the character's efforts in the face of the harassment. The collected data was then analyzed using descriptive analysis method. There are three theories used which are the Theory of Sociology Literature of Wiyatmi (2013), Harassment Theory of Beran \& Li (2002) and Semiotics Theory of Danesi (2004). The results of the data analysis shows that in the Eiji Harasumento drama there is a repeated form of harassment but it is done by different characters. $70 \%$ harassment is a direct harassment whereas $30 \%$ is indirect harassment. Verbal direct harassment is found in $85 \%$ from all of direct harassment. While a partly data show is nonverbal direct harassment. Mostly direct harassment is doing by superiors and colleagues on female characters, but there are also data showing harassment by subordinates to superiors in the Eiji Harasumento drama. While overall of indirect harassment doing by fellow woman either by superiors or women of the same position.Then the character's efforts in dealing with abuse are mostly shown by the female characters either directly or indirectly efforts.
\end{abstract}

Keywords : direct harassment, indirect harassment, workplace harassment 


\section{Latar Belakang}

Pelecehan merupakan suatu sikap atau perilaku yang tidak dikehendaki baik secara verbal maupun fisik yang dilakukan oleh pelakunya dengan tujuan kesenangan namun tidak diinginkan dan dikehendaki oleh korbannya, serta dianggap sebagai sesuatu yang mengancam kesejahteraan secara fisik, psikologis, sosial dan ekonomi (Soerjotomo, 2016: 41). Di Jepang, pelecehan khususnya pelecehan di tempat kerja terus meningkat setiap tahunnya. Berdasarkan laporan yang disampaikan oleh Kementrian Kesehatan, Tenaga Kerja dan Kesejahteraan Jepang (厚生労 働省 atau kousei roudou shou) pada tahun 2002 terjadi 6.627 kasus pelecehan. Jumlah tersebut meningkat pesat pada tahun 2012 menjadi 51.670 kasus (Nito, 2014: 113). Pelecehan di tempat kerja yang sering terjadi diakibatkan oleh penyalahgunaan jabatan sehingga memunculkan istilah power harassment atau pawa hara di kalangan pekerja di Jepang. The Japan Institute for Labour Policy and Training (JILPT) tahun 2011 melaporkan bahwa dari 284 kasus konsiliasi mengenai pelecehan sebanyak $39,8 \%$ nya merupakan pelecehan terhadap pria dan $59,8 \%$ merupakan pelecehan terhadap wanita.

Fenomena ini menjadi inspirasi banyak sastrawan untuk membuat karya sastra bertema pelecehan. Eiji Harasumento merupakan salah satu karya Uchidate Makiko yang mengangkat tema plecehan yang terjadi di lingkungan kerja dengan beragam bentuk dan upaya para tokoh untuk mengatasi.

\section{Pokok Permasalahan}

Permasalahan yang dibahas pada penelitian ini adalah bentuk harassment yang terjadi dalam drama Eiji Harasumento. Selain itu juga meneliti mengenai upaya para tokoh dalam drama untuk mengatasi harassment.

\section{Tujuan Penelitian}

Tujuan penelitian ini untuk memberikan informasi kepada pembaca mengenai perilaku pelecehan. Selain itu untuk mengetahui bentuk-bentuk pelecehan dan upaya para tokoh dalam mengatasi pelecehan yang tercemin dalam drama Eiji Harasumento.

\section{Metode Penelitian}

Metode yang digunakan dalam analisis data adalah metode deskriptif analisis yaitu metode yang dilakukan dengan cara menguraikan dan memberikan penjelasan mengenai faktafakta yang kemudian disusul dengan analisis yang tidak semata-mata menguraikan melainkan juga memberikan pemahaman dan penjelasan secukupnya (Ratna, 2006: 53). Data berupa dialog dan potongan gambar dianalisis dengan menggunakan teori sosiologi sastra Wiyatmi (2013), teori Harassment dari Beran \& Li (2002). Serta teori Semiotika Danesi (2004) digunakan untuk menunjang penganalisisan tanda dalam drama.

\section{Hasil dan Pembahasan}

Penelitian ini menganalisis pelecehan yang terjadi di lingkungan kerja yaitu sebuah perusahaan perdagangan di Jepang.Hasil penelitian ini menjabarkan bentuk harassment dan upaya tokoh dalam mengatasi harassment tersebut dengan menggunakan teori harassment dari Beran \& Li (2002) sebagai acuan.

\subsection{Bentuk-bentuk Harassment}

Berdasarkan teori harassment, dalam drama Eiji Harasumento ditemukan bentuk harassment yang terbagi menjadi dua yaitu direct harassment berkisar $70 \%$ sedangkan indirect harassment sebesar $30 \%$ dari keseluruhan data mengenai pelecehan. 


\subsubsection{Direct Harassment}

Direct harassment merupakan perilaku pelecehan yang dilakukan secara langsung dan terang-terangan bahkan dapat meliputi penyerangan fisik. Direct harassment dalam drama Eiji Harasumento dibagi menjadi direct harassment verbal dan non verbal. Pelecehan langsung secara verbal terjadi sebanyak $85 \%$ dari keseluruhan data mengenai pelecehan langsung. Pelecehan verbal ini dilakukan terhadap pria dan wanita yang dilakukan oleh atasan maupun rekan kerja yang berkedudukan sama. Pelecehan tersebut meliputi penghinaan usia dan bentuk fisik, penghinaan dengan perumpaan, meremehkan serta mengambil alih pekerjaan seseorang.

Sedangkan direct harassment non verbal terjadi sebesar $15 \%$ yang dilakukan oleh atasan baik pria maupun wanita terhadap bawahannya, selain itu terdapat juga pelecehan yang dilakukan oleh bawahan terhadap atasannya. Pelecehan non verbal ini meliputi perilaku membatasi interaksi sosial, mencegah pengembangan karir, penyerangan langsung dan sentuhan yang tidak diinginkan.Berikut ini adalah contoh data dari direct harassment verbal yang dilakukan atasan pria terhadap bawahan wanita serta contoh data pelecehan non verbal yang dilakukan bawahan terhadap atasannya.

(1) 浅野誠：もう君レベルのおば さん派遣なんてね掃 きだめにダンゴムシ になるぐらいいるん だからね。

(第 7 課、39 分、35 秒)

Asano Makoto : Mou kimi reberu no obasan haken nante ne, haki dame ni dango mushi ni naru gurai irundakara ne.

(Dai 7 ka, 39 fun, 35 byou)

Asano Makoto : Seorang karyawan wanita tua sepertimu, seperti serangga di tempat pembuangan sampah.

(Episode 7, menit 39.35 detik)

Data (1) menunjukkan pelecehan yang dilakukan Asano yaitu memanggil Abe dengan sebutan obaasan yang berarti nenek dan mengumpamakannya sebagai dango mushi yaitu serangga yang hidup di tempat sampah. Panggilan obaasan ditujukan pada wanita yang memiliki usia yang terpaut cukup jauh dengan si pemanggil, namun Asano hanya terpaut lebih muda 3 tahun dari Abe (54). Sehingga pemanggilan ini menjadi pelecehan terhadap Abe dari Asano. Hasil survei dari Impress Corporation menunjukkan umumnya orang Jepang memanggil orang lain dengan sebutan obaasan ketika seorang wanita berusia 70 hingga 74 tahun. Selain itu, wanita juga lebih sensitif dengan sebutan obaasan. Hasil survei yang dipublikasikan melalui website seniorguide.jp memaparkan bahwa $14,8 \%$ wanita enggan disebut obaasan bahkan ketika usia wanita tersebut sudah menginjak usia tua. Maka dari itu cara Asano memanggil Abe merupakan tindak pelecehan, selain itu perkataan ini juga berdampak pada perasaan tidak nyaman yang dirasakan Abe. 


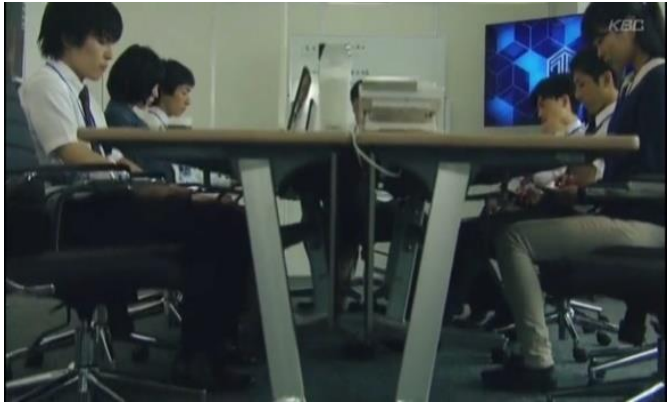

Gambar (1) Peserta rapat yang sibuk menggunakan ponsel ketika rapat

(Episode 5, menit 15.46 detik)

Gambar (1) menunjukkan pelecehan non verbal yang dilakukan secara langsung oleh peserta rapat yang merupakan bawahan Komori terhadap Komori selaku atasan dan pemimpin rapat mereka. Para peserta rapat menunduk dan menggunakan ponsel mereka di bawah meja secara diam-diam agar Komori tidak mengetahuinya. Mereka mengacuhkan dan mengesampingkan arahan yang diberikan Komori secara serius dan lebih mengutamakan mengakses ponsel. Sikap yang ditunjukkan peserta rapat ini mengindikasikan pelecehan terhadap Komori.

\subsubsection{Indirect Harassment}

$\begin{array}{ccc}\text { Indirect } & \text { harassment yang } \\ \text { ditemukan dalam drama Eiji }\end{array}$ Harasumento secara keseluruhan dilakukan oleh sesama wanita. Indirect harassment terjadi sebanyak 30\% dari jumlah keseluruhan data pelecehan yang terjadi dalam drama Eiji Harasumento. Pelecehan tidak langsung tersebut berupa tindakan memengaruhi orang lain untuk membenci, menyebarkan rumor, pemberian julukan dan tindakan pengucilan. Berikut merupakan salah satu contoh data yang menunjukkan pelecehan tidak langsung dalam drama Eiji Harasumento yang dilakukan oleh wanita terhadap rekan kerjanya sesama wanita.

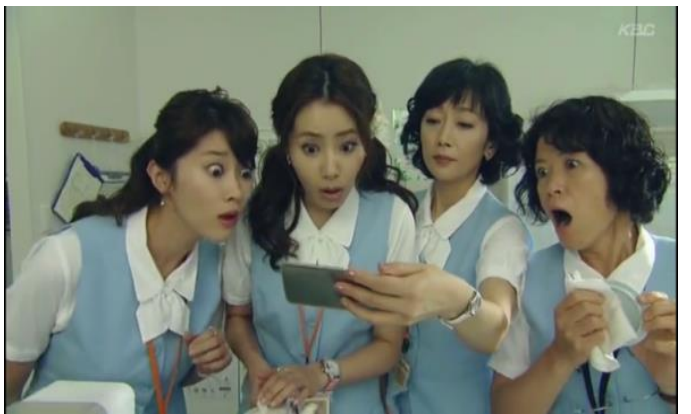

Gambar (2) Nakazato menujukkan foto Yoshii dan Hoshina di sebuah restoran (Episode 3, menit 44:56 detik)

Gambar (2) merupakan potongan adegan ketika Nakazato menunjukkan foto antara Yoshii dan Hoshina yang sedang berdekatan di sebuah restoran. Nakazato tidak mengetahui kepastian mengenai kejadian tersebut, namun secara sepihak ia menyimpulkan bahwa Yoshii dan Hoshina sedang berkencan. Keterkejutan mengenai kabar yang diberikan Nakazato terlihat dari ekspresi wajah ketiga wanita lainnya. Terlihat mimik wajah yang terkejut seperti mata yang melotot dan mulut yang terbuka lebar.

Tindakan yang dilakukan Nakazato memberi dampak tidak menyenangkan bagi Yoshii. Sebab karena rumor yang disebarkan Nakazato, Yoshii menerima perlakuan sinis dan kebencian dari rekanrekannya yang merasa cemburu karena Yoshii dapat dekat dengan pria yang memiliki jabatan tinggi. Kedekatan Yoshii ini membuat rekan-rekannya berusaha melecehkan Yoshii dengan cara membuat julukan terhadapnya.

(2)野田ミカ : 吉井さんつて商売人レ ベルだね。

(第 5 課、 21 分、 48 秒)

Noda Mika : Yoshii san tte shôbainin reberu dane.

(Dai 5 ka, 21 fun, 48 byou)

Noda Mika : Yoshii mencapai level "nyonya rumah" ya. 
(Episode 5, menit 21.48 detik)

Data (2) merupakan pelecehan yang dilakukan Noda terhadap Yoshii karena merasa bahwa Yoshii selalu berusaha mencari perhatian dengan ikut pada acara nomikai meskipun dalam acara itu tidak ada rekan wanitanya yang ikut. Pelecehan ini dilakukan dengan menjuluki Yoshii sebagai shoubainin atau nyonya rumah. Namun nyonya rumah yang dimaksud bukanlah tuan rumah dalam arti positif. Kata ini memiliki makna seorang wanita yang secara professional bekerja pada bisnis dunia malam. Pelecehan yang dilakukan rekannya menimbulkan perasaa kesal dan tidak nyaman bagi Yoshii. Karena sesungguhnya ia tidak memiliki niat seperti yang dituduhkan oleh rekannya tersebut.

\subsection{Upaya Tokoh Menghadapi Harassment}

Dalam penelitian ini, ditemukan upaya tokoh dalam menghadapi tindak pelecehan yang terbagi menjadi dua yaitu upaya yang dilakukan secara langsung sebesar $80 \%$ dan upaya yang dilakukan secara tidak langsung sebesar $20 \%$ dari upaya yang dilakukan tokoh dalam drama Eiji Harasumento. Upaya menghadapi pelecehan dalam drama Eiji Harasumento sebagian besar dilakukan oleh tokoh wanita

\subsubsection{Upaya yang dilakukan secara langsung}

Upaya menghadapi harassment yang dilakukan tokoh dalam drama Eiji Harasumento secara langsung meliputi tindakan mengajukan pembelaan diri, melakukan sindiran, melakukan perlawanan verbal langsung dan mengungkapkan kejahatan pelaku pelecehan. Berikut dijabarkan contoh databerupa mengajukan pembelaan diri sebagai upaya menghadapi harassment yang dilakukan secara langsung.
(3) 菊池あけみ : 私ら残業も出張も転

勤が嫌なんで一般

職を希望したんで

す。

（第 4 課、10 分、 31 秒）

Kikuchi Akemi :Watashira zangyou mo shucchou mo tenkin ga iyanande ippan shoku wo kibou shitan desu.

(Dai 4 ka, 10 fun, 31 byou)

Kikuchi Akemi : Kami tidak mau bekerja lembur, dipindah tugaskan dan melakukan perjalanan bisnis itulah yang diharapkan karyawan wanita biasa.

(Episode 4, menit 10.31 detik)

Data (3) merupakan pembelaan yang dilakukan Kikuchi, yaitu salah satu karyawan departemen teksil golongan ippan shoku yang berulang kali menerima pelecehan dari managernya yaitu Oda. Di Jepang, karyawan wanita terbagi menjadi dua golongan yaitu sogo shoku dan ippan shoku.

Wanita yang memilih sogo shoku lebih mengutamakan karir sehingga mereka bersedia meskipun harus jauh dari rumah dalam waktu yang lama. Disisi lain, ippan shoku berarti karyawan wanita yang hanya ditugaskan. Kategori ini dipilih oleh wanita yang lebih mengutamakan keluarga daripada pekerjaan. Pekerja wanita pada kategori ini bekerja pada tingkat subordinat sehingga berperan tidak begitu penting dan memiliki gaji yang rendah (Kumagai, 1996: 114).

Perlawanan ini dilakukan Kikuchi ketika dirinya hendak pulang karena jam 
kerja telah usai namun Oda memaksanya untuk mengerjakan sebuah tugas tambahan. Kikuchi merasa dirinya berhak untuk tidak melakukan pekerjaan tersebut karena sesuai golongan yang ia pilih, ippan shoku tidak setara dengan karyawan laki-laki sehingga tidak diharuskan untuk lembur. Kikuchi melawan Oda bahkan di depan semua orang untuk memperjuangkan haknya.

\subsubsection{Upaya yang dilakukan secara tidak langsung}

Dalam drama Eiji Harasumento upaya untuk menghadapi pelecehan yang dilakukan oleh tokoh secara tidak langsung meliputi tindakan berupa mengembangkan kemampuan dan memperbaiki diri sendiri. Berikut pemaparan contoh data yang menunjukkan keinginan tokoh untuk berkembang sebagai upaya menghadapi pelecehan secara tidak langsung.

(4)吉井英美里 : 課長、私にもつと仕

事をさせて頂けま

せんか。もっと働

けます。私は繊維 部門を希望して入 社しましたけど総 務に配属された以 上総務で頑張ろう と思っています。 でも先を見て鍛え てもらっていると はおもいません。

（第 1 課、32 分、54 秒）

Yoshii Emiri : Kacho, watashi ni motto shigoto o sasete

itadakemasenka?

Motto hatarakemasu.

Watashi wa sen $i$

bumon o kibou shite

nyuusha shimashita

kedo, soumu ni

haizoku sareta ijou soumu de ganbarou to omotte imasu. Desukedo saki o mite kitaete moratte iru to wa omoimasen.

(Dai 1 ka, 32 fun, 54 byou)

Yoshii Emiri : Manager, bisakah anda memberikan saya lebih banyak tugas ? Saya bisa bekerja lebih banyak. Saya berharap dapat bergabung dengan departemen tekstil, namun sampai saatnya, saya berpikir akan melakukan yang terbaik di departemen urusan umum. Namun, saya berpikir saya belum cukup berlatih.

(Episode 1, menit 32.54 detik)

Data (4) merupakan perkataan yang diucapkan Yoshii pada Osawa selaku atasannya. Yoshii berharap diberikan pekerjaan yang lebih agar dapat memberinya lebih banyak wawasan dan keterampilan. Ia selama beberapa bulan bekerja hanya ditugaskan untuk menyediakan teh, mengecek ruang rapat, mengerjakan tugas administrasi dan pekerjaan ringan lainnya.

Pekerjaan yang terkesan mudah namun Yoshii yang dapat menjadi idola di kalangan karyawan pria menimbulkan kecemburuan dari rekannya kerjanya. Sehingga Yoshii ingin mengembangkan kemampuannya dan mengerjakan pekerjaan yang lebih sulit agar tidak lagi dilecehkan oleh rekan-rekannya. 


\section{(6) Simpulan}

Berdasarkan analisis pada data-data yang ditemukan maka dapat disimpulkan bahwa bentuk harassment dan upaya tokoh menghadapi harassment yang terdapat dalam drama Eiji Harasumento secara garis besar terbagi menjadi dua yaitu langsung dan tidak langsung. Pelecehan langsung atau direct harassment terbagi lagi menjadi dua yaitu direct harassment verbal dan non verbal.

Berdasarkan pelecehan yang terjadi dalam drama Eiji Harasumento, direct harassment verbal tercermin melalui tindakan penghinaan usia dan bentuk fisik, penghinaan dengan perumpamaan, meremehkan serta mengambil alih pekerjaan seseorang. Sedangkan direct harassment non verbal meliputi perilaku membatasi interaksi sosial, mencegah pengembangan karir, penyerangan langsung dan sentuhan yang tidak diinginkan. Sedangkan indirect harassment tergambar melalui tindakan memengaruhi orang lain untuk membenci, menyebarkan rumor, pemberian julukan dan tindakan pengucilan.

Kemudian upaya menghadapi harassment yang dilakukan secara langsung oleh tokoh dalam drama meliputi tindakan mengajukan pembelaan diri, melakukan sindiran, melakukan perlawanan verbal langsung dan mengungkapkan kejahatan pelaku pelecehan. Sedangkan upaya untuk menghadapi pelecehan yang dilakukan secara tidak langsung meliputi tindakan berupa mengembangkan kemampuan dan memperbaiki diri sendiri.

\section{(7) Daftar Pustaka}

Beran, T \& Qing Li. 2002. Cyber Harassment: A Study of a New Method for an Old Behavior. Journal of Educational Computing Research

Danesi, Marcel. 2004. Messages, Signs, And Meaning: A Basic Textbook in
Semiotics And Communication Theory 3rd Edition. Toronto: Canadian Scholars' Press Inc.

Kumagai, Fumie. 1996. Unmasking

Japan Today : the Impact of Traditionl

Values on Modern Japanese Society.

London : Praeger

Nito, Shino. 2014. Workplace Bullying in Japan. Kyoto: The Japan Institute for Labour Policy and Training

Ratna, Nyoman Kutha. 2006. Teori, Metode, dan Teknik Penelitian Sastra. Cetakan Kedua. Yogyakarta: Pustaka Pelajar

Soerjotomo. 2016. Pencegahan dan Penanggulang Diskriminasi di Tempat Kerja. Jakarta: Kementrian Tenaga Kerja dan Transmigrasi R.I

Wiyatmi. 2013. Sosiologi Sastra: Kanwa Publisher 